\title{
A retrospective classification of diagnoses in terms of DSM-5 for patients included in randomized controlled trials of Ginkgo biloba extract EGb 761 ${ }^{\circledR}$
}

\author{
Robert Hoerr ${ }^{1} \cdot$ Michael Zaudig $^{2}$
}

Received: 24 February 2015 / Accepted: 3 August 2015 / Published online: 13 August 2015

(C) The Author(s) 2015. This article is published with open access at Springerlink.com

\begin{abstract}
When the early trials of Ginkgo biloba extract EGb $761{ }^{\circledR}$ were conducted, different terms were used to denote ageing-associated neurocognitive disorders. With the fifth edition of the Diagnostic and Statistical Manual of Mental Disorders (DSM-5), a taxonomy covering dementia and pre-dementia stages of such disorders became available. DSM-5 diagnostic criteria for neurocognitive disorders (NCDs) were applied to patients with any type of ageing-associated cognitive impairment, including dementia, enrolled in randomized controlled clinical trials of EGb $761^{\circledR}$, taking into account the reported inclusion and exclusion criteria and patient characteristics at baseline. For 23 of 31 trials $(74 \%)$, the inclusion diagnoses could be classified as NCD in accordance with DSM-5. Thirteen trials enrolled patients with major NCD, four trials enrolled patients with mild NCD and six trials enrolled patients with NCD, who could not be classified unambiguously as having mild or major NCD. Although various terms were formerly used for neurocognitive disorders, the patients enrolled in the majority of clinical trials with EGb $761^{\circledR}$ could be classified retrospectively using modern DSM-5 diagnostic criteria.
\end{abstract}

Electronic supplementary material The online version of this article (doi:10.1007/s00406-015-0632-y) contains supplementary material, which is available to authorized users.

Robert Hoerr

robert.hoerr@schwabe.de

1 Clinical Research Department, Dr. Willmar Schwabe GmbH \& Co. KG, Willmar-Schwabe-Str. 4, 76227 Karlsruhe, Germany

2 Klinik Windach, Schuetzenstr. 100, 86949 Windach, Germany
Keywords DSM-5 - Diagnosis $\cdot$ Dementia $\cdot$ Mild cognitive impairment $\cdot$ Ginkgo biloba $\cdot$ EGb $761^{\circledR}$

\section{Introduction}

When the earliest clinical trials of the defined, quantified Ginkgo biloba extract EGb $761^{\circledR}$ and some other drugs, then called "nootropics", were conducted during the 1970 s and 1980s, there was no widely accepted diagnostic term, let alone consensus diagnostic criteria, for what was later called "ageing-associated cognitive decline" (AACD) [1], "cognitive impairment no dementia" (CIND) [2] or "mild cognitive impairment" (MCI) [3, 4]. For cognitive impairment in the elderly, vaguely defined terms were often used, e.g.: "organic brain syndrome", "cerebral insufficiency", "impairment of cerebral performance", "Hirnleistungsstörungen" (German), "troubles du vieillissement cérébral" (French) or, when associated with cerebrovascular disease, "cerebrovascular insufficiency". The DSM-III [5] already provided a description and diagnostic criteria for dementia and research diagnostic criteria for Alzheimer's disease (AD) [6] and vascular dementia (VaD) [7] followed soon. The DSM criteria have been revised repeatedly (DSM-III-R [8]; DSM-IV [9]). In addition to the DSM criteria, the diagnostic criteria of the International Classification of Diseases (ICD-10) [10] were also used in clinical trials. A comparison of these sets of criteria is provided in Table 1. In spite of the availability of diagnostic criteria and related nomenclature, there was continued reluctance among European clinicians to assign a diagnosis of dementia to a patient, as dementia was perceived as stigmatizing. Hence, descriptive terms that were neither precisely defined nor part of the thesaurus of a systematic classification of diseases were often used for conditions 


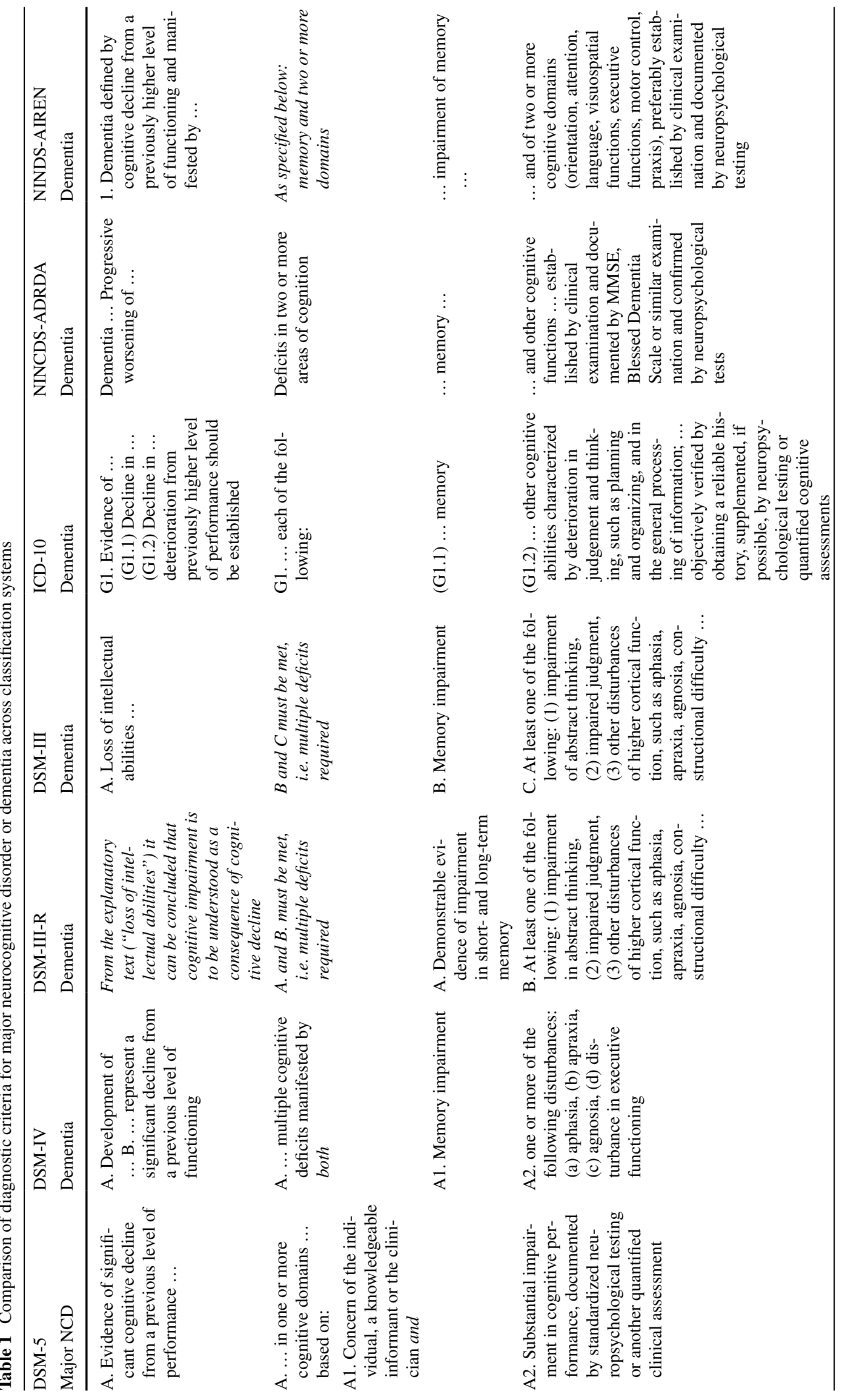




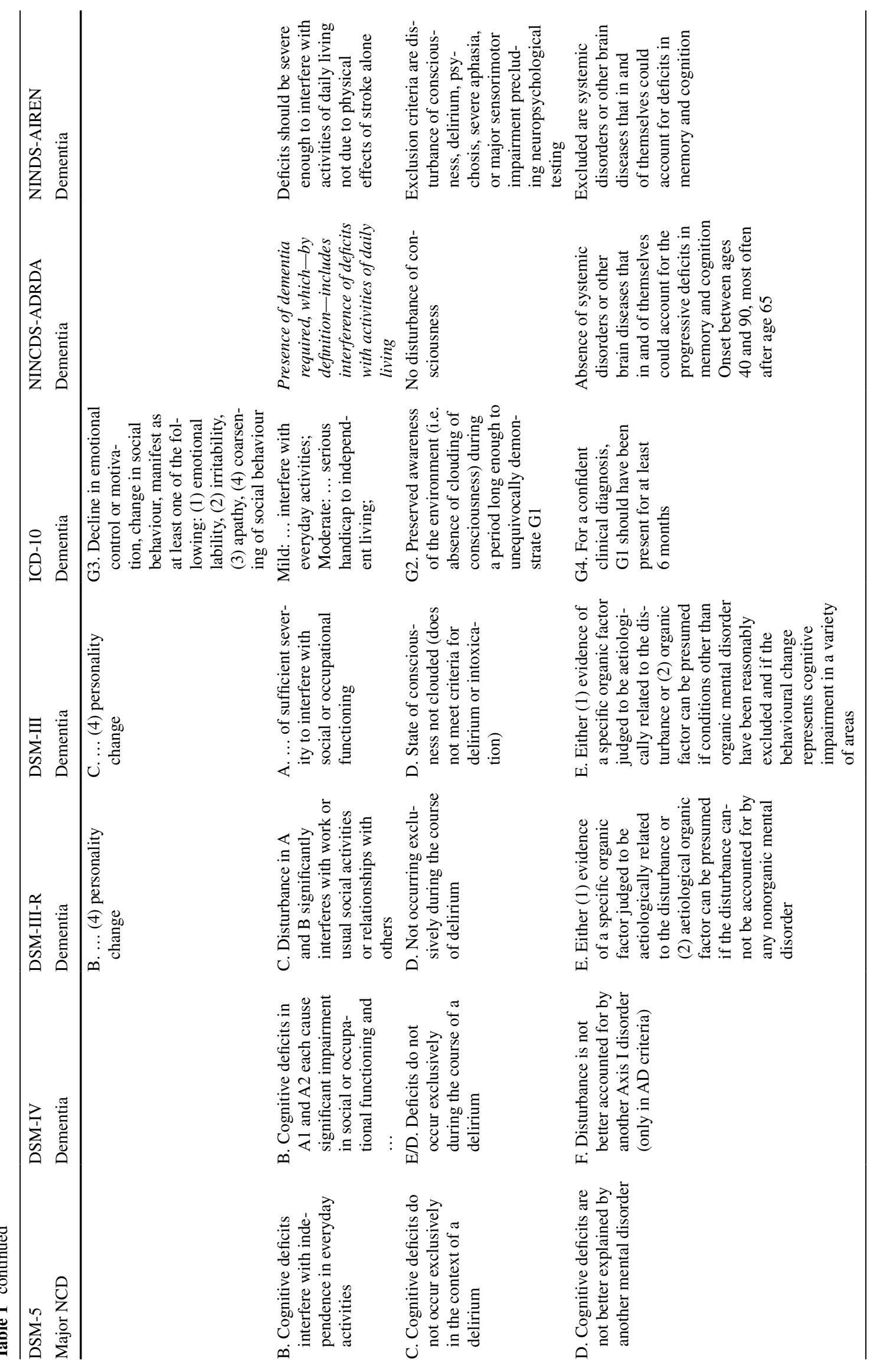


along the continuum of $\mathrm{MCI}$ and dementia until the end of the millennium. As a consequence, it was difficult to gauge whether patients enrolled in different clinical trials in fact had different disorders or whether different terms for the same disorder were being used in different publications.

Until recently, in contrast to dementia, the pre-dementia stages of neurocognitive disorders were poorly accounted for by disease classifications. Whereas the various types of dementia were classified as distinct entities with specific aetiologies in earlier editions of the DSM and the International Classification of Diseases (ICD), a heterogeneous collection of conditions between healthy ageing and dementia was subsumed under the term MCI. It was only in 2007 that Dubois and colleagues [11] took a "longitudinal" perspective when preparing a revision of the NINCDSADRDA criteria for Alzheimer's disease. They proposed prodromal or MCI stages corresponding to each aetiologically defined dementia disorder. Similarly, with the change from DSM-IV to DSM-5, the classification was refined to cover the whole range of disorders from clear-cut MCI to full-blown dementia under the category "neurocognitive disorders" (NCDs) [12]. There is now provision (although not a strict requirement) for aetiological differentiation within both "mild neurocognitive disorder" (representing the MCI stage) and "major neurocognitive disorder" (representing dementia). From an ethical point of view, it is noteworthy that the new nomenclature no longer uses the term "dementia", which has been perceived as pejorative and stigmatizing [13].

The question addressed by this research is to what extent the inclusion diagnoses and criteria applied in clinical trials of G. biloba extract EGb $761^{\circledR}$ fit within the new DSM-5 taxonomy. Using published information and, as far as needed and available, unpublished data, we retrospectively classified the patients enrolled in randomized controlled trials of EGb $761{ }^{\circledR}$ in terms of DSM-5 diagnostic categories.

\section{Methods}

Published papers on all randomized controlled trials of EGb $761{ }^{\circledR}$ in cognition-related ailments and disorders were retrieved. These were identified by a comprehensive literature search in the context of the call for scientific data on G. biloba for assessment by the Committee on Herbal Medicinal Products (HMPC) of the European Medicines Agency in October 2011. All available information about diagnostic terms, diagnostic criteria, inclusion and exclusion criteria, presence and actual severity of cognitive and functional impairment at baseline was retrieved at study level and checked against the DSM-5 criteria for major NCD and mild NCD and their aetiological sub-classes. If an unambiguous classification was not possible from the published information, the original clinical trial reports were retrieved, as far as available, and information relevant to diagnostic classification was extracted at patient and study level, as appropriate.

\section{Major NCD}

The diagnosis of major NCD is based on four main criteria, A-D, and two sub-criteria to criterion A (A1, A2). Criterion A requires a "significant cognitive decline from a previous level of performance in one or more cognitive domains", evidence of which should be based on the two sub-criteria. A1 specifies that the "concern of the individual, a knowledgeable informant or the clinician" should be present; A2 "a substantial impairment in cognitive performance". Both A1 and A2 must be met. Furthermore, the following are also mandatory: interference of cognitive deficits "with independence in everyday activities" (criterion B), occurrence not "exclusively in the context of a delirium" (criterion C) and that the "cognitive deficits are not better explained by another mental disorder" (criterion D).

In a substantial number of trials, the diagnosis of dementia, probable $\mathrm{AD}$, probable $\mathrm{VaD}$ or possible $\mathrm{AD}$ with cerebrovascular disease (CVD) was established in accordance with DSM-III, DSM-III-R, ICD-10, NINCDS-ADRDA or NINDS-AIREN, as applicable. Therefore, the various sets of diagnostic criteria used in the included studies were compared to determine how and to what extent criteria of the DSM-5 correspond to criteria of the other classifications and whether fulfilment of DSM-5 criteria can be concluded from the fulfilment of corresponding criteria of other classifications. Additional information from inclusion and exclusion criteria, neuropsychological tests and rating scales supporting the diagnosis of major NCD was presented in the published reports on these trials.

If none of the sets of diagnostic criteria mentioned above was employed, all pertinent information, such as inclusion and exclusion criteria, means and distributions of actual test and rating scale scores, was utilized to check whether the criteria for major NCD were met.

\section{Mild NCD}

The diagnosis of mild NCD is also based on four main criteria, A to D, and two sub-criteria to criterion A (A1, A2). Criterion A requires a "modest cognitive decline from a previous level of performance in one or more cognitive domains", evidence of which should be derived from the two sub-criteria. A1 specifies that the "concern of the individual, a knowledgeable informant or the clinician" should be present; A2 "a modest impairment in cognitive performance". Both A1 and A2 must be met. Moreover, it is 
mandatory that the cognitive deficits "do not interfere with capacity for independence in everyday activities" (criterion B), "do not occur exclusively in the context of a delirium" (criterion C) and are "not better explained by another mental disorder" (criterion D).

The consensus criteria for MCI [4] that were employed in one trial [14] explicitly cover criteria A (including A1 and A2) and B. From the exclusion criteria reported in the published paper, it is evident that criteria $\mathrm{C}$ and $\mathrm{D}$ were also met by the enrolled patients. The eligibility criteria of the other trials with patients who were cognitively impaired but not demented were as variable as the diagnostic terms assigned. Hence, all available information was utilized to check whether the criteria for mild NCD were met.

\section{Aetiological sub-classes}

Testing for $\mathrm{AD}$ genetic mutations or genetically determined vascular disorders was not performed in any of the studies, nor was a specific family history documented. Hence, the classification of NCD due to probable or possible AD was mainly based on the course of the disease ["insidious onset and gradual progression" (criteria B and C2b), "clear evidence of decline in memory and learning" (criteria B and C2a)], lacking evidence of mixed aetiology (criterion C2c) and the fact that the disturbance is not better explained by another disorder (criterion D).

The classification of vascular NCD mainly relies on the temporal relationship of its onset to one or more cerebrovascular events (criterion B1) or evidence for a prominent decline in complex attention and frontal-executive function (criterion B2), evidence of the presence of cerebrovascular disease (criterion $\mathrm{C}$ ) and the fact that the symptoms are not better explained by another disorder (criterion D). In the absence of genetic testing, the probability of vascular origin is assessed by neuroimaging and the temporal relationship with one or more cerebrovascular events.

The NINCDS-ADRDA criteria for probable Alzheimer's disease cover the DSM- 5 criteria A, B, C2 and D for major NCD due to probable Alzheimer's disease. The NINDSAIREN criteria cover the DSM-5 criteria A, B1, C and $\mathrm{D}$ and the probability criterion 2 for probable major vascular NCD. Possible AD (NINCDS-ADRDA) with CVD (NINDS-AIREN) can be classified under major NCD due to multiple aetiologies (specifically $\mathrm{AD}$ and CVD). In all trials that used the NINCDS-ADRDA and/or NINCDSAIREN criteria, further information supporting the aetiological sub-classification was available from neuroimaging.

In studies not employing NINCDS-ADRDA and/or NINDS-AIREN criteria, all available information was utilized to check whether the DSM-5 criteria for aetiological sub-categories were met.

\section{Results}

A total of 31 randomized controlled trials of $G$. biloba extract EGb $761^{\circledR}$ in elderly patients with various degrees of cognitive impairment were identified. The inclusion diagnoses of 23 trials (74\%) could be classified as NCD. In four trials, the presence of NCD was likely, but could not be ascertained beyond doubt, and in four trials, the criteria for NCD were not met.

\section{Studies in major NCD}

The diagnostic criteria for major NCD or dementia of the classifications used in the included trials are presented in Table 1, arranged in a way to highlight the features in common and the differences. Some salient differences are: (a) only DSM-5 specifies that "the individual, a knowledgeable informant or the clinician" has to show concern about the cognitive decline; (b) DSM-5 requires deficits in one or more domains, whereas all other sets of criteria require impairment in at least two or even more than two (NINDSAIREN) domains; (c) DSM-5 is the only classification that allows a diagnosis of dementia without overt memory impairment- - "unusual nonamnestic presentations... also exist"; (d) the NINCDS-ADRDA criteria do not explicitly mention interference with activities of daily living, but presence of dementia is required, with "dementia" usually being understood as cognitive decline severe enough to interfere with professional and/or social activities.

The DSM-5 criteria A2, B and C could be assumed to be met if any of the other classifications listed in Table 2 was used in a study. Fulfilment of criterion A1 was usually concluded from the patients seeing a clinician and undergoing examinations and diagnostic procedures. The DSM-III-R criteria for dementia in general do not explicitly require that there be a decline in cognitive abilities (criterion A), but the explanatory text mentions a loss in intellectual abilities and the criteria for both AD and MID require deterioration in cognitive performance in order to establish the diagnosis. The ICD-10 criterion G4, specifying that the cognitive decline should have been present for at least 6 months for a confident diagnosis of dementia, seems to have a similar intention, but is not explicit in saying that there should be no better explanation for the cognitive deficits than dementia. The ICD-10 criteria were used in one of the included studies, and the patients of this study also had to meet the DSM-III-R criteria. Overall, it can be concluded that all patients diagnosed with dementia using one of the sets of criteria listed in Table 1 can safely be classified as having major NCD in accordance with DSM-5.

Thirteen trials (42\%) enrolled patients that could be classified unambiguously as having major NCD. In nine of 


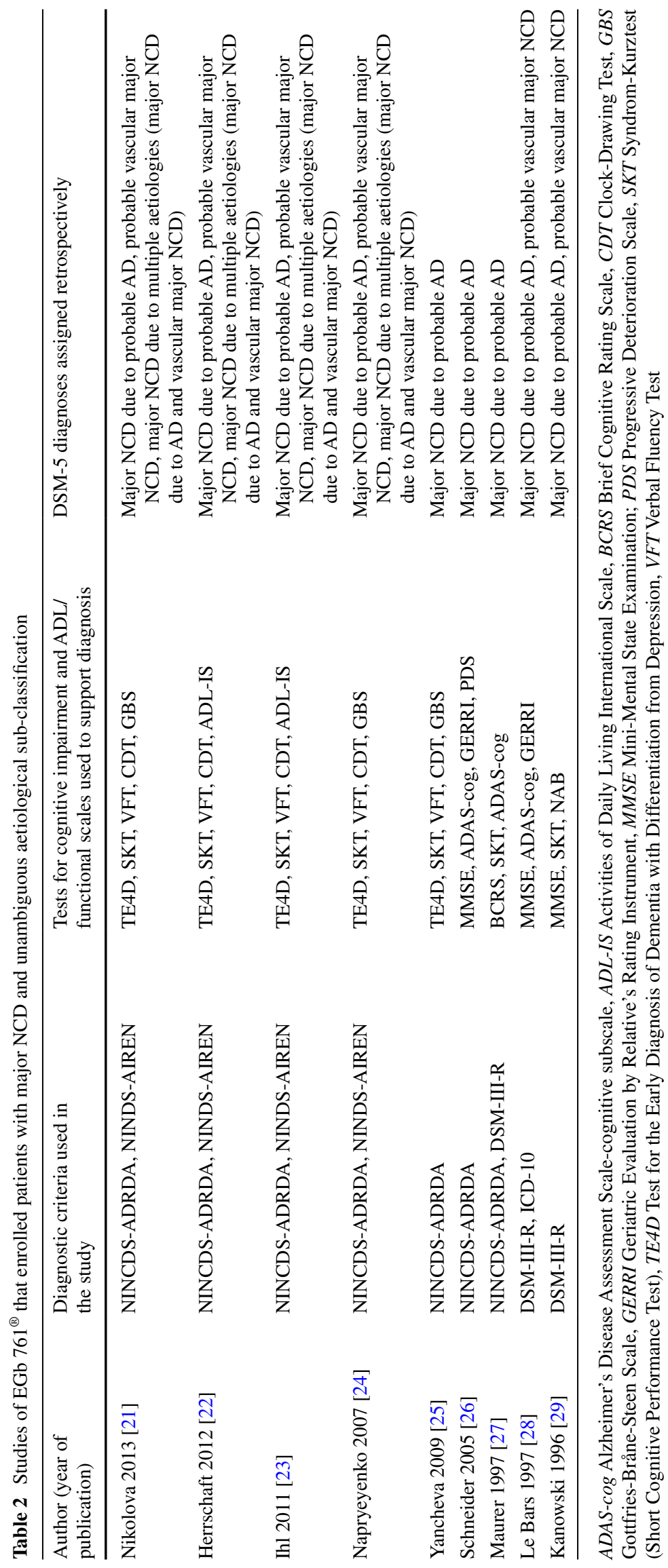


Table 3 Studies of EGb $761{ }^{\circledR}$ that enrolled patients with major NCD, aetiological sub-classification not entirely certain or not made

\begin{tabular}{|c|c|c|c|}
\hline Author (year of publication) & $\begin{array}{l}\text { Diagnostic criteria } \\
\text { used in the study }\end{array}$ & $\begin{array}{l}\text { Tests for cognitive impairment } \\
\text { and ADL/functional scales used } \\
\text { to support diagnosis }\end{array}$ & $\begin{array}{l}\text { DSM-5 diagnoses assigned retro- } \\
\text { spectively }\end{array}$ \\
\hline Rai 1991 [30] & NINCDS-ADRDA & $\begin{array}{l}\text { MMSE, Kendrick battery for the } \\
\text { detection of dementia }\end{array}$ & Major NCD due to $\mathrm{AD}^{\mathrm{a}}$ \\
\hline Haase 1996 [31] & DSM-III-R & MMSE, GDS, KAI, NAB, NAA & $\begin{array}{l}\text { Major NCD due to probable } \mathrm{AD} \text {, } \\
\text { possible vascular major NCD }\end{array}$ \\
\hline Weitbrecht and Jansen 1986 [32] & Not specified & $\begin{array}{l}\text { WAIS digit symbol substitu } \\
\text { tion test, WAIS digit span test, } \\
\text { SCAG, Crichton Geriatric Scale }\end{array}$ & $\begin{array}{l}\text { Major NCD (most likely due to } \\
\text { AD) }\end{array}$ \\
\hline Oswald 1997 [33] & DSM-III & SCAG, NAI & $\begin{array}{l}\text { Major NCD (no aetiological sub- } \\
\text { classification was made) }\end{array}$ \\
\hline
\end{tabular}

a Patients were diagnosed in accordance with NINCDS-ADRDA criteria, but the authors did not specify whether probable AD or possible AD or both were accepted

b The inclusion diagnosis assigned by the clinician was "primary degenerative dementia", which was then used synonymously with dementia of the Alzheimer type, but diagnostic criteria were not specified. Hence, not all DSM-5 criteria for aetiology could be verified. The acceptable range for the Hachinski Ischaemic Score (up to 7) supports the clinical diagnosis of Alzheimer's disease, but does not strictly exclude mixed AD/ vascular aetiology

GDS Global Deterioration Scale, KAI Kurztest für Allgemeine Intelligenz (Short Test for General Intelligence), MMSE Mini-Mental State Examination, $N A A$ Nürnberger Alters-Alltags-Skala (Nuremberg Gerontopsychological Self-Rating Scale for Activities of Daily Living), NAB Nürnberger Alters-Beobachtungs-Skala (Nuremberg Gerontopsychological Observation Scale for Activities of Daily Living), NAI Nürnberger AltersInventar (Nuremberg Gerontopsychological Inventory), SCAG Sandoz Clinical Assessment-Geriatric, WAIS Wechsler Adult Intelligence Scale

Table 4 Studies of EGb $761^{\circledR}$ that accepted patients with NCD without clear distinction between major NCD and mild NCD

\begin{tabular}{ll}
\hline Author (year of publication) & DSM-5 diagnoses \\
\hline Gräßel $1992[34]$ & Possible vascular major NCD, possible vascular mild NCD \\
Halama 1988 [35] & Possible vascular major NCD, possible vascular mild NCD \\
Hofferberth 1994 [36] & Major NCD, mild NCD (aetiological sub-classification uncertain) \\
Schubert and Halama 1993 [37] & Major NCD, mild NCD (no aetiological sub-classification was made) \\
Israël 1987 [38] & Major NCD, mild NCD (no aetiological sub-classification was made) \\
Wesnes 1987 [39] & Major NCD, mild NCD (no aetiological sub-classification was made) \\
\hline
\end{tabular}

a The inclusion diagnosis assigned by the clinician was "senile dementia of the Alzheimer type", but diagnostic criteria are not specified. Hence, not all DSM-5 criteria could be verified. According to inclusion criteria and data recorded at baseline, more than $75 \%$ of patients had major NCD, for $25 \%$ this could not be verified beyond doubt. Cognitive deficits, Hachinski Ischaemic Score and CT scan support the clinical diagnosis of Alzheimer's disease

these trials the aetiological sub-classifications also meet the criteria set by DSM-5 (Table 2), in three trials the aetiological sub-classification could not be confirmed beyond doubt, and in one trial no sub-classification was made (Table 3). If more than one aetiological category was acceptable for a trial, the aetiological sub-classification was always made prospectively.

\section{Studies in major or mild NCD}

Six trials (19\%) enrolled patients who could be classified unambiguously as having NCD, but interference of the cognitive deficits with independence in everyday activities (criterion B) was not completely clear (Table 4). Hence, no strict distinction between mild NCD and major NCD can be made. In two of these studies, the DSM-5 criteria for possible vascular NCD are fulfilled.

\section{Studies in mild NCD}

Patients meeting DSM-5 criteria for mild NCD were enrolled in four trials (13\%) (Table 5). No aetiological sub-classification was made in these trials.

\section{Studies in patients not classified by DSM-5}

Eight studies (26\%) enrolled patients who could not be classified unambiguously as having NCD in accordance with DSM-5 diagnostic criteria (Table 6). This does not necessarily mean that these patients did not have NCD; it 
Table 5 Studies of EGb $761^{\circledR}$ that enrolled only patients with mild NCD

\begin{tabular}{ll}
\hline Author (year of publication) & DSM-5 diagnoses \\
\hline Gavrilova 2014 [14] & Mild NCD (no aetiological sub-classification was made) \\
Grass-Kapanke 2011 [40] & Mild NCD (no aetiological sub-classification was made) \\
Allain 1993 [41] & Mild NCD (no aetiological sub-classification was made) \\
Stocksmeier and Eberlein 1992 [42] & Mild NCD (no aetiological sub-classification was made) \\
\hline
\end{tabular}

Table 6 Studies of EGb $761^{\circledR}$ enrolling patients not classifiable by DSM-5

\begin{tabular}{ll}
\hline Author (year of publication) & Original diagnosis \\
\hline van Dongen 2003 [43] & Age-associated memory impairment (AAMI), dementia ${ }^{\mathrm{a}}$ \\
Hofferberth 1991 [44] & Organic brain syndrome with increased vascular risk \\
Halama 1990 [45] & Cerebrovascular insufficiency \\
Hofferberth 1989 [46] & Organic brain syndrome \\
Taillandier 1986 [47] & Chronic cerebral insufficiency \\
Eckmann and Schlag 1982 [48] & Cerebrovascular insufficiency \\
Dieli 1981 [49] & Chronic cerebral insufficiency \\
Moreau 1975 [50] & Chronic insufficiency of cerebral circulation \\
\hline
\end{tabular}

a The main inclusion diagnosis was AAMI, which could be mild NCD; a small proportion of patients were assigned a diagnosis of dementia applying DSM-III-R and ICD-10 criteria by nursing home staff not trained to diagnose dementia. The SKT scores were in the range typical for mild-to-moderate dementia, which renders the high rate of AAMI questionable. On the other hand, interference with activities of everyday life was denied for most patients. In the absence of laboratory tests and neuroimaging, the possibility of conditions other than AAMI or dementia must be taken into account and any classification in terms of NCD would be imprudent only means that the information provided was not sufficient to safely conclude that all included patients had NCD.

\section{Discussion}

Using available diagnostic and other descriptive information, predominantly from published papers, the patients of most (74\%) randomized controlled trials of G. biloba extract EGb $761^{\circledR}$ could be classified in terms of the new DSM-5 diagnostic categories. As expected, a high proportion of trials in major NCD (nine out of 13) allowed an unambiguous aetiological sub-classification at the "probable" level (Table 2); in three trials the level of certainty was lower than "probable", and only one trial in major NCD did not classify the patients by aetiology (Table 3). In contrast, no aetiological sub-classification was made in the four trials enrolling only patients with mild NCD (Table 5). This reflects the presence of aetiological sub-classes for dementia, but not for pre-dementia stages of cognitive impairment, in earlier classifications of mental disorders. For two of the six trials that admitted both major NCD and mild NCD, an unambiguous classification as vascular NCD was possible, and for another one a classification as NCD due to $\mathrm{AD}$ was reasonably likely.

Using mainly inclusion and exclusion criteria and severity information at study level for classification, a patient sample was classified under mild or major NCD and under an aetiological sub-group only if all patients met the respective criteria. Our procedure can therefore be regarded as conservative. If the inclusion diagnosis in terms of mild or major NCD or aetiology could not be ascertained for the whole study sample, this study population remained unclassified with respect to mild or major NCD (Table 4) or with respect to aetiology (Table 3).

The new DSM-5 concept integrates the early (predementia) and later (dementia) stages of aetiologically different neurocognitive disorders with the common core feature "cognitive decline" within one common framework. The studies that admitted both patients with mild NCD and those with major NCD reflect a problem that has not been resolved completely by the DSM-5, i.e. a precise definition and operationalization of interference of the cognitive deficits with independence in everyday activities. Since the 1980s, the distinction between MCI and dementia or mild NCD and major NCD has been refined considerably, yet room for interpretation still remains. Interestingly, the Herbal Medicinal Products Committee (HMPC) of the European Medicines Agency (EMA) overcame this problem by phrasing the therapeutic indication for well-established use of G. biloba leaf extract as follows: "improvement of (age-associated) cognitive impairment and of quality of life in mild dementia" [15]. It thus acknowledges that there is evidence of efficacy from randomized 
controlled trials in both MCI and dementia or, in other words, mild NCD and major NCD.

By re-grouping patient samples of older studies in terms of DSM-5 diagnostic categories, well-defined and widely accepted diagnoses could be assigned to the patients of a considerable number of clinical trials in which old-fashioned and vaguely defined diagnostic terms were originally used. This does not immediately change the overall knowledge base concerning the efficacy of EGb $761^{\circledR}$, but it enables comparisons between studies of different periods in time and appropriate aggregation of trials for systematic reviews and meta-analyses. As recently accomplished for dementia [16], a meta-analysis can now be conducted across studies of patients with mild NCD. The new classification also helps younger clinicians and researchers understand which types of patients were enrolled in studies conducted more than two decades ago.

Interestingly, a comparison of various sets of diagnostic criteria for dementia and major NCD found a high concordance, allowing a DSM-5 diagnosis of major NCD in a high proportion of patients who were diagnosed with dementia according to the older classifications. There is, however, no complete congruence between the classifications, with DSM-5 tending to be more inclusive than earlier classifications. Patients diagnosed, e.g. as having major NCD due to probable $\mathrm{AD}$ or probable vascular major NCD by DSM-5, would not necessarily meet the more elaborate NINCDSADRDA criteria for probable AD or NINDS-AIREN criteria for probable $\mathrm{VaD}$.

Using the DSM-5 diagnostic term "neurocognitive disorder", where appropriate, helps overcome some of the problems associated with the use of terms such as "dementia" or (cerebral, cerebrovascular) "insufficiency", which are widely perceived as stigmatizing and devaluing [13, 17]. First, dementia (defined as deterioration or loss of the intellectual faculties, the reasoning power, the memory, and the will [18]) is an inappropriate term for the early stages of NCDs during which full independence or at least a large capacity to manage everyday life is retained. Second, a considerable number of family physicians are still reluctant to diagnose dementia and to communicate this diagnosis to patients and their families, due to the stigma associated not only with the disease itself, but with the term dementia in particular $[17,19]$. On the other hand, the change in terminology implemented by psychiatrists, but not neurologists (e.g. NINCDS-ADRDA revision [11]; NIA-AA criteria [20]) may render communication and collaboration of neurologists and psychiatrists in the field of neurodegenerative diseases more difficult.

It is a particular strength of our research that DSM-5 diagnoses were assigned only if the available information permitted the verification of all pertinent diagnostic criteria for the whole patient sample. This means that the patients classified retrospectively met the same criteria as those that patients enrolled in clinical trials today are required to meet. A limitation is the retrospective approach, because the interpretation of today's DSM-5 criteria may not be exactly the same as the interpretation of corresponding inclusion criteria stipulated 20 years ago. Moreover, increased awareness of the risk of developing NCD and refined diagnostic procedures may lead to higher proportions of very mildly affected patients in today's specialized centres that recruit patients to clinical trials. However, similar variability between patient samples from different trials is to be expected even in the case of prospective diagnosis. This is likely to result from differences in the types of patients available at different clinical sites and the possibility of some diversity in interpretation of the diagnostic criteria in various regions with different cultures.

In conclusion, the new classification and nomenclature of the DSM-5 could be applied successfully to assign modern, consistent and meaningful diagnostic terms to elderly patients with cognitive impairments enrolled in clinical trials over the past two and a half decades. The patients of $74 \%$ of the randomized controlled trials of G. biloba extract EGb $761^{\circledR}$ identified by a comprehensive literature search could be retrospectively classified by matching selection criteria and baseline data to the DSM-5 diagnostic criteria.

\section{Compliance with ethical standards}

Conflict of interest $\mathrm{RH}$ receives a fixed salary as an employee of Dr. Willmar Schwabe GmbH \& Co. KG, the manufacturer of EGb $761^{\circledR}$; MZ provided scientific advice to Dr. Willmar Schwabe $\mathrm{GmbH} \& \mathrm{Co}$. KG and received consultancy fees.

Open Access This article is distributed under the terms of the Creative Commons Attribution 4.0 International License (http://creativecommons.org/licenses/by/4.0/), which permits unrestricted use, distribution, and reproduction in any medium, provided you give appropriate credit to the original author(s) and the source, provide a link to the Creative Commons license, and indicate if changes were made.

\section{References}

1. Levy R, Working Party of the International Psychogeriatric Association in collaboration with the World Health Organization (1994) Report: aging-associated cognitive decline. Int Psychogeriatr 6:63-68

2. Ebly EM, Hogan DB, Parhad IM (1995) Cognitive impairment in the nondemented elderly: results from the Canadian study of health and aging. Arch Neurol 52:612-619

3. Petersen RC, Smith GE, Waring SC, Ivnik RJ, Tangalos EF, Kokmen E (1999) Mild cognitive impairment: clinical characterization and outcome. Arch Neurol 56:303-308

4. Winblad B, Palmer K, Kivipelto M, Jelic V, Fratiglioni L, Wahlund LO, Nordberg A, Bäckman L, Albert M, Almkvist O, Arai 
H, Basun H, Blennow K, De Leon M, DeCarli C, Erkinjuntti T, Giacobini E, Graff C, Hardy J, Jack C, Jorm A, Ritchie K, Van Duijn C, Visser P, Petersen RC (2004) Mild cognitive impairment-beyond controversies, towards a consensus: report of the International Working Group on Mild Cognitive Impairment. J Intern Med 256:240-246

5. American Psychiatric Association (1980) Diagnostic and statistical manual of mental disorders, 3rd edn. American Psychiatric Association, Washington, DC

6. McKhann G, Drachman D, Folstein M, Katzman R, Price D, Stadlan EM (1984) Clinical diagnosis of Alzheimer's disease: report of the NINCDS-ADRDA Work Group under the auspices of Department of Health and Human Services Task Force on Alzheimer's Disease. Neurology 34:939-944

7. Román GC, Tatemichi TK, Erkinjuntti T, Cummings JL, Masdeu JC, Garcia JH, Amaducci L, Orgogozo JM, Brun A, Hofman A, Moody DM, O'Brien MD, Yamaguchi T, Grafman J, Drayer BP, Bennett DA, Fischer M, Ogata J, Kokmen E, Bermejo F, Wolf PA, Gorelick PB, Bick KL, Pajeau AK, Bell MA, DeCarli C, Culebras A, Korczyn AD, Bogousslavsky J, Hartmann A, Scheinberg P (1993) Vascular dementia: diagnostic criteria for research studies: Report of the NINDS-AIREN International Workshop. Neurology 43:250-260

8. American Psychiatric Association (1987) Diagnostic and statistical manual of mental disorders, 3rd edn. American Psychiatric Association, Washington

9. American Psychiatric Association (1994) Diagnostic and statistical manual of mental disorders, 4th edn. American Psychiatric Association, Washington

10. World Health Organization (1992) International statistical classification of diseases and related health problems: tenth revision. World Health Organization, Geneva

11. Dubois B, Feldman HH, Jacova C, DeKosky ST, BarbergerGateau P, Cummings J, Delacourte A, Galasko D, Gauthier S, Jicha G, Meguro K, O'Brien J, Pasquier F, Robert P, Rossor M, Salloway S, Stern Y, Visser PJ, Scheltens P (2007) Research criteria for the diagnosis of Alzheimer's disease: revising the NINCDS-ADRDA criteria. Lancet Neurol 6:734-746

12. American Psychiatric Association (2013) Diagnostic and statistical manual of mental disorders, 5th edn. American Psychiatric Association, Arlington

13. Kurz AF, Lautenschlager NT (2010) The concept of dementia: retain, reframe, rename or replace? Int Psychogeriatr 22:37-42

14. Gavrilova SI, Preuss UW, Wong JWM, Hoerr R, Kaschel R, Bachinskaya N, GIMCIPlus Study Group (2014) Efficacy and safety of Ginkgo biloba extract EGb $761{ }^{\circledR}$ in mild cognitive impairment with neuropsychiatric symptoms: a randomized, placebo-controlled, double-blind, multi-center trial. Int J Geriatr Psychiatry 29:1087-1095. doi:10.1002/gps.4103

15. European Medicines Agency (2014) Community herbal monograph on Ginkgo biloba L., folium: draft. European Medicines Agency, London

16. Gauthier S, Schlaefke S (2014) Efficacy and tolerability of Ginkgo biloba extract EGb $761^{\circledR}$ in dementia: a systematic review and meta-analysis of randomized placebo-controlled trials. Clin Interv Aging 9:2065-2077

17. Phillips J, Pond CD, Paterson NE, Howell C, Shell A, Stocks NP, Goode SM, Marley JE (2012) Difficulties in disclosing the diagnosis of dementia: a qualitative study in general practice. Br J Gen Pract 62:e546-e553. doi:10.3399/bjgp12X653598

18. Hoerr NL, Osol A (eds) (1952) Blakiston's illustrated pocket medical dictionary. McGraw-Hill, New York

19. Burns A, Iliffe S (2009) Dementia. BMJ 338:b75

20. McKhann GM, Knopman DS, Chertkow H et al (2011) The diagnosis of dementia due to Alzheimer's disease: recommendations from the National Institute on Aging-Alzheimer's Association workgroups on diagnostic guidelines for Alzheimer's disease. Alzheimer's Dement 7:263-269

21. Nikolova G, Yancheva S, Raychev I, Hoerr R, PLAGIN Study Group (2013) Ginkgo biloba extract in dementia: a 22-week randomized, placebo-controlled double-blind trial. Bulg Neurol 14:139-143

22. Herrschaft H, Nacu A, Likhachev S, Sholomov I, Hoerr R, Schlaefke S (2012) Ginkgo biloba extract EGb $761^{\circledR}$ in dementia with neuropsychiatric features: a randomized, placebo-controlled trial to confirm the efficacy and safety of a daily dose of $240 \mathrm{mg}$. J Psychiatr Res 46:716-723

23. Ihl R, Bachinskaya N, Korczyn AD, Vakhapova V, Tribanek M, Hoerr R, Napryeyenko O, GOTADAY Study Group (2011) Efficacy and safety of a once-daily formulation of Ginkgo biloba extract EGb $761^{\circledR}$ in dementia with neuropsychiatric features: a randomized controlled trial. Int J Geriatr Psychiatry 26:11861194. doi:10.1002/gps.2662

24. Napryeyenko O, Borzenko I, GINDEM-NP Study Group (2007) Ginkgo biloba special extract in dementia with neuropsychiatric features: a randomized, placebo-controlled, double-blind clinical trial. Arzneim Forsch/Drug Res 57:4-11

25. Yancheva S, Ihl R, Nikolova G, Panayotov P, Schlaefke S, Hoerr R, GINDON Study Group (2009) Ginkgo biloba extract EGb $761^{\circledR}$, donepezil or both combined in the treatment of Alzheimer's disease with neuropsychiatric features: a randomised, double-blind, exploratory trial. Aging Ment Health 13:183-190

26. Schneider LS, DeKosky ST, Farlow MR, Tariot PN, Hoerr R, Kieser M (2005) A randomized, double-blind, placebo-controlled trial of two doses of Ginkgo biloba extract in dementia of the Alzheimer's type. Curr Alzheimer Res 2:541-551

27. Maurer K, Ihl R, Dierks T, Frölich L (1997) Clinical efficacy of Ginkgo biloba special extract EGb 761 in dementia of the Alzheimer type. J Psychiatr Res 31:645-655

28. Le Bars PL, Katz MM, Berman N, Itil TM, Freedman AM, Schatzberg AF, North American EGb Study Group (1997) A placebo-controlled, double-blind randomized trial of an extract of Ginkgo biloba for dementia. JAMA 278:1327-1332

29. Kanowski S, Herrmann WM, Stephan K, Wierich W, Hörr R (1996) Proof of efficacy of the Ginkgo biloba special extract EGb 761 in outpatients suffering from mild to moderate primary degenerative dementia of the Alzheimer type or multi-infarct dementia. Pharmacopsychiatry 29:47-56

30. Rai GS, Shovlin C, Wesnes KA (1991) A double-blind placebocontrolled study of Ginkgo biloba extract ("Tanakan") in elderly outpatients with mild to moderate memory impairment. Curr Med Res Opin 12:350-355

31. Haase J, Halama P, Hörr R (1996) Efficacy of short-term treatment with intravenously administered Ginkgo biloba special extract EGb 761 in Alzheimer type and vascular dementia. Z Gerontol Geriatrie 29:302-309

32. Weitbrecht WU, Jansen W (1986) Primär degenerative Demenz: therapie mit Ginkgo-biloba-Extrakt placebokontrollierte doppelblind-und vergleichsstudie. Fortschr Med 104:199-202

33. Oswald WD, Hörr R, Oswald B, Steger W, Sappa J (1997) Zur Verbesserung fluider, kognitiver Leistungen mit Ginkgo-bilobaSpezialextrakt EGb $761{ }^{\circledR}$ bei Patienten mit leichten bis mittelschweren Hirnleistungsstörungen im Alter. Z Gerontopsychol Psychiatrie 3:133-146

34. Gräßel E (1992) Einfluß von Ginkgo-biloba-Extrakt auf die geistige Leistungsfähigkeit. Fortschr Med 110:73-76

35. Halama P, Bartsch G, Meng G (1988) Hirnleistungsstörungen vaskulärer Genese: Randomisierte Doppelblindstudie zur Wirksamkeit von Ginkgo-biloba-Extrakt. Fortschr Med 106:408-412

36. Hofferberth B (1994) The efficacy of EGb 761 in patients with senile dementia of the Alzheimer type, a double-blind, 
placebo-controlled study on different levels of investigation. Hum Psychopharmacol 9:215-222

37. Schubert H, Halama P (1993) Primär therapieresistente depressive verstimmung älterer patienten mit hirnleistungsstörungen: Wirksamkeit der Kombination von Ginkgo-biloba-Extrakt EGb 761 mit Antidepressiva. Geriatr Forsch 3:45-53

38. Israël L, Dell'Accio E, Martin G, Hugonot R (1987) Extrait de Ginkgo biloba et exercises d'entrainement de la mémoire. Psychol Méd 19:1431-1439

39. Wesnes K, Simmons D, Rook M, Simpson P (1987) A doubleblind placebo-controlled trial of Tanakan in the treatment of idiopathic cognitive impairment in the elderly. Hum Psychopharmacol 2:159-169

40. Grass-Kapanke B, Busmane A, Lasmanis A, Hoerr R, Kaschel R (2011) Effects of Ginkgo biloba special extract EGb $761{ }^{\circledR}$ in very mild cognitive impairment (vMCI). Neurosci Med 2:48-56

41. Allain H, Raoul P, Lieury A, LeCoz F, Gandon JM (1993) Effect of two doses of Ginkgo biloba extract (EGb 761) on the dualcoding test in elderly subjects. Clin Ther 15:549-558

42. Stocksmeier U, Eberlein M (1992) Depressive verstimmung bei hirnleistungsstörungen: wirkung eines Ginkgo-biloba—extraktes in doppelblind-studie überprüft. TW Neurol Psychiatr 6:74-76

43. van Dongen M, van Rossum E, Kessels A, Sielhorst H, Knipschild P (2003) Ginkgo for elderly people with dementia and age-associated memory impairment: a randomized clinical trial. J Clin Epidemiol 56:367-376

44. Hofferberth B (1991) Simultanerfassung elektrophysiologischer, psychometrischer und rheologischer Parameter bei Patienten mit hirnorganischem Psychosyndrom und erhöhtem GefäßrisikoEine placebokontrollierte Doppelblindstudie mit Ginkgo-bilobaExtrakt EGb 761. In: Stodtmeister R, Pillunat LE (eds) Mikrozirkulation in Gehirn und Sinnesorganen. Enke, Stuttgart, pp 64-74

45. Halama P (1990) Therapie mit Ginkgo biloba bei patienten mit cerebrovaskulärer insuffizienz und therapieresistenter depressiver symptomatik: Was leistet der Spezialextrakt (EGb 761)? Therpiewoche 40:3760-3765

46. Hofferberth B (1989) Einfluß von Ginkgo biloba-Extrakt auf neurophysiologische und psychometrische Messergebnisse bei Patienten mit hirnorganischem Psychosyndrom: Eine Doppelblindstudie gegen Placebo. Arzneim Forsch/Drug Res 39:918-922

47. Taillandier J, Ammar A, Rabourdin JP, Ribeyre JP, Pichon J, Niddam S, Pierart H (1986) Traitement des troubles du vieillissement cérébral par l'extrait de Ginkgo biloba: Etude longitudinale multicentrique à double insu face au placebo. Presse Méd 15:1583-1587

48. Eckmann F, Schlag H (1982) Kontrollierte Doppelblind-Studie zum Wirksamkeitsnachweis von Tebonin forte bei Patienten mit zerebrovaskulärer Insuffizienz. Fortschr Med 100:1474-1478

49. Dieli G, LaMantia V, Saetta M, Constanzo E (1981) Studio clinico in doppio cieco del Tanakan nell' insufficienza cerebrale cronica. Lav Neuropsychiatr 68:3-15

50. Moreau P (1975) Un nouveau stimulant circulatoire cérébral. Nouv Presse Méd 4:2401-2402 